\title{
Design and Implementation of University Performance Management System based on Cloud Computing Technology
}

\author{
Wang Kechao ${ }^{1,2^{*}}$, Zhu Ruijie ${ }^{1}$, Jia Zongfu ${ }^{1}$ and Ren Xiangmin ${ }^{1}$ \\ ${ }^{1}$ School of information engineering, Harbin University, Harbin, China \\ ${ }^{2}$ School of computer science and technology, Harbin Institute of Technology, Harbin, China \\ aerickcwang@126.com, b614266960@qq.com, '814033480@qq.com, 'miin0070@sina.com
}

Keywords: Performance Management System; Grading audit; Custom template

\begin{abstract}
In recent years, colleges and universities around the world have begun to pay more and more attention to the performance appraisal. Therefore, A scientific, reasonable and universal performance management system has a far-reaching impact and significance on improving teachers' performance and achieving the goals of colleges and universities. At present, due to the different scoring standards of colleges and universities, the performance management systems are customized according to the needs of colleges and universities. The development cost is high and the maintainability is poor. There is no general performance management system. In this context, based on JavaEE and Struts $2+$ Spring+Hibernate technology, a performance management system based on cloud computing for university teachers is designed based on custom templates, improving the generality and scalability.
\end{abstract}

\section{Introduction}

The new round of wage system reform is to change from "identity management" to "post management", establishing a performance-oriented salary system with post responsibility, job performance and actual contribution closely linked. There are two kinds of excellent teachers' performance management systems. The first one is represented by "Yoso Performance Appraisal System". The second one is represented by "Beishen Performance Cloud", "800 Customers CRM". The first kind of system has the advantage of deep customization and customization of personalized performance management system to meet the needs of schools. The disadvantage is that the service form or traditional IT service is the main solution, the host computer in the school, there is no strong universality. The second category is just the opposite, according to the general characteristics, but not for the development of teachers, not fully meet the needs of teacher performance management. Relatively outstanding companies in foreign countries have "review snap" performance management system, "SAP Success Factors" and "PeopleSoft". PeopleSoft system has strong comprehensive function and stability, but the product price and service cost are expensive, and it is difficult to adapt to the structure and management mode of domestic university performance system. Under this background, we design and implement a cloud university teacher performance management system.

\section{System Architecture}

The system uses Model-View-Controller architecture and Apache Tomcat to publish the website. The system network architecture is shown in Figure 1.

\section{System Design}

System cloud registration module. The system can at least complete the registration of school account, user account, etc. The school user registration page mainly includes the name of the school, the basic information of the person in charge, the telephone number, and the certificate of qualification of the relevant institutions, etc. User registration pages for ordinary individual teachers mainly include personal information filling, mobile phone number, in-school job number, password 
and so on. The business logic layer mainly includes LoginServlet and RegisterServlet.Logical service layer receives the phone number filled in by ordinary personal teacher user in the presentation layer through Class RegisterServlet. After clicking the send authentication code, the server accepts the number and sends the authentication code to the mobile phone. The LoginServlet class receives encapsulated User objects (including mobile phone numbers and authentication codes or user-independent numbers and passwords) and passes them to UserService, which compares the data accepted by the server to the contents of the database and returns the comparison results to the LoginServlet class, which compares with the database The result is returned to the presentation layer.

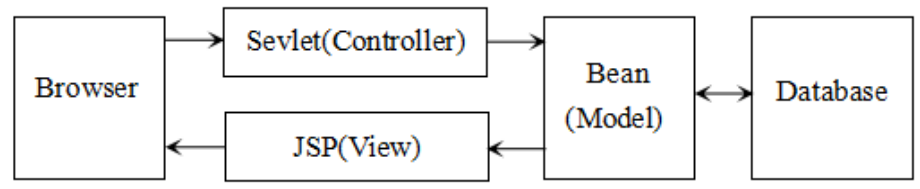

Figure 1 System Architecture

System login module. The system has three kinds of users: ordinary teacher user, department administrator and school administrator, providing a unified login port. Pages include user identity selection, phone number / user name, password, etc. The layer includes UserServiceImpl, CheckService and LoginServlet business classes. Ordinary teacher users receive the user ID sent from the display page or the phone number and password filled in by the UserServiceImpl class. The LoginServlet class receives the encapsulated TeacherUseInfo object and passes it to the UserDaoImpl class. The login method in UserDaoImpl returns to the LoginServlet class after processing, and the LoginServlet class returns the result to the Login. Jsp page presentation layer. The CheckService of the school user receives the wrapped SchoolInfo object from the page presentation layer and passes it to the SchoolInforDaoImpl class, returning the result information from the database query to the presentation layer and popping up the corresponding feedback. After being authenticated, the administrators and administrators can jump to different pages and provide different functions.

System password modification module. It provides users with a variety of functions to modify their passwords to protect users' information security. Pages include mobile phone number or user's current login ID, authentication code or old password and new password. The user clicks the modified password button on the upper left corner of the personal page and pops out the corresponding page. The business layer includes PwdModServlet business classes. The PwdModServlet class will receive the encapsulated TeacherUserInfo object and pass it to the PwdModService class. The method in the PwdModService will return after processing. Back to the PwdModServlet class, the PwdModServlet class returns the result of the modified password processing to the page.

Privilege grading audit module. When the user with audit authority opens the audit interface, he can see the classification and prompt of all the documents to be audited, and can filter according to the time order or the status of approval, which is convenient for approval. The audit page has many filtering and search options for users to facilitate daily work, selective and purposeful filtering approval of relevant documents. Through the PaperSerlvet and other related classes for approval, the front-end click on the agreement, the parameters will be sent to the background for the relevant approval operation, the background ApprovService modifies database content, to achieve the purpose of preservation.

User management module. Users can pop up user information. The modification information can be input in the pop-up window to achieve the modification effect. After the user enters the system, click the user management tab to enter the user management interface. The user management interface can see all the user information. Click the modify/view button next to it, pop up the details pop-up window, and enter the details in the pop-up window. Encapsulate the data sent from the front office to the background. Background ChangUserInfo class receives objects, parses them, determines identity information and modifies types, and imports different results into the database for persistent storage. UserInfoService is responsible for the query and modification of the relevant personnel in the data access layer, and returns the operation results to the business layer. 
Department management module. System administrators can set up or adjust relevant departments. The page is composed of tabs and sub pages. Administrators click on the Department Management tab to see the relationship and details of the current departments. Click on the faculties to see details and make adjustments. The DepartmentServlet class receives objects in the background and parse objects. Through the FindDepartment method in DepartmentService, send the details and relations of the Department to the front desk. Through the Change Department method in DepartmentService, the foreground modified content is transferred to the background storage database.

Menu editing module. System administrators who have permission to log on to the system, can carry out their own departments settings. The menu editing management page displays the switch state of menu and function by two columns of switches, and judges whether the function is turned on according to the switch shape and left and right color. Switch state is switched by clicking switch. The MenuServlet class receives objects in the background and parse objects. Through the FindMenu method in MenuService, send the details and relations of the Department to the front desk. Through the ChangeMenu method in MenuService, the foreground modified content is transferred to the background storage database. The layer includes the MenuService class, which stores the previously mentioned content in a database in Sql form and returns the results back to the front page.

Grading of research and teaching achievement module. The achievements can be divided into two modules: scientific research and teaching. On this basis, the two major categories are further subdivided. For example, scientific research achievement is subdivided into paper management, patent management, famous teacher management, academic works management and so on. These small items can be set by school administrators and department administrators as needed, and can be switched on and off in the menu management function. Scientific research and teaching achievement management respectively have their own management pages, through the above screening conditions can be classified and screened. Teacher users can upload the attachments to the results within the corresponding functions, and administrators can see the research and teaching results uploaded by teachers. The background SciRearchServlet and TeachingServlet class receive and analyze the objects coming from the foreground. FindPaper in SciRearchService and other methods send the type of detailed information list and relationship to the foreground. Through the method of SciRearch, the foreground modified content is transferred to the background storage database.

Grading criteria for individualized setting of departments module. Initialize a score template when an organization account is created, and schools can modify the score criteria according to their requirement. Department administrators can also have your own template, which can be modified based on the school template. In the administrator interface, the score can be set. FindScores and other methods in ScoreService can send detailed information list and relationship to the front desk. By changing Scores in ScoreService and other methods, the foreground modified content is transferred to the background storage database.

Activity publishing management module. Activities are divided into school activities and departmental activities, such as year-end performance appraisal and job evaluation, etc. The page mainly includes audit items, audit limits, activity deadlines, etc. When the hospital level or school level is released, does the front JavaScript verify that the activities released are meeting the actual requirements. If the requirement is met, the Activity Service is called layer by layer with Activity Servlet, and the Activity Dao layer is called to insert the requirement and information of the activity into the database and send the activity message to the teacher user. Teacher users are required to submit activities, if the submitted work does not meet the requirements of the college or school-level submission of works, it will have to be resubmitted. The layer includes the ActivityDao data class, which receives encapsulated objects from the business layer and queries and modifies them in the database, and returns the modified results to the business layer.

\section{System Testing}

The performance management system is tested, mainly testing the functions of user registration, login, menu editing, teaching and research achievements upload, activities release, performance approval 
and so on. After unit testing, system testing, conditional testing and boundary testing, the system functions meet expectations.

\section{Conclusion}

Based on JavaEE and S2SH framework technology, a cloud university teacher performance management system is designed. The system realizes the main functions of uploading and statistics of scientific research and teaching achievements, grading audit of the separation of colleges and universities, general scoring template, flexible menu editing, and self-defining publishing assessment activities. The person in charge of the college or university can publish custom activities and restrict the results required by the activities in terms of time, grade, category and quantity. Teachers are required to upload the results within the scope of activities, and the uploaded results need to be audited and scored. The person in charge of a college can assign the examination authority to the scientific research and teaching secretary to assist in the audit work. After the scheduled time arrives, the system will rank according to the performance score after the audit, and get the evaluation results. This system successfully solves the problem of universality in performance management in most colleges, and improves the inconvenience of performance statistics for the majority of teachers.

\section{Acknowledgement}

This work was supported in part by Research Fund for the Innovative Scholars of Harbin Grant No.2016RAQXJ013.

\section{Reference}

[1] Lu Zhixia. Research on Problems and Countermeasures of Performance Review for Teachers in Universities[J].Modern Education Management, 2013, (08): 78-82.

[2] Zhang Lu. Design and implementation of University Teacher' performance appraisal management system [D]. Hunan University, 2018: 1-70.

[3] Li Nan. The Research of University Teacher' Performation Evaluation in Our Country --Mainly to The Teaching Performance Evaluation[D]. Capital University of Economics and Business, 2012:1-219.

[4] Xia Maolin. The Comparison and Thinking of Performance Evaluation System of College Teachers in America and England [J]. Journal of Educational Science of Hunan Normal University. 2011, (01):74-77.

[5] Zheng Yunxiang, etc. Research of Performance Evaluation of University Teachers' Adaptability on ICT-based Teaching [J]. China's foreign capital.2018, 373(2):21-28.

[6] Ouyang Hongji, etc. Application Research of Java Web based on Struts2 and Hibernate Framework[J]. Automation Technology and Applications, 2016, 35(02): 48-52.

[7] Li Jinglong. Design and Implementation of Vocational College Performance Management System Based on Lightweight J2EE[D]. Hebei University of Science and Technology, 2017:1-63.

[8] Zhang Hang. The design and implementation of the management system of the automatic performance of the Southwest Network Company of the Civil Aviation[D]. University of Electronic Science and Technology of China, 2018:1-82.

[9] Wang Xuqiang. Design and implementation of performance management software system based on J2EE[D]. Jilin University, 2016:1-96.

[10] Luan Zheng. Design and Implementation of performance management system for $\mathrm{B} / \mathrm{S}$ structure[D]. Dalian University of Technology, 2016:1-74. 